\title{
Erratum to: Three-dimensional probability maps of the rhinal and the collateral sulci in the human brain
}

\author{
Sonja C. Huntgeburth ${ }^{1,2}$ - Michael Petrides ${ }^{1,2}$
}

Published online: 1 August 2016

(C) Springer-Verlag Berlin Heidelberg 2016

\section{Erratum to: Brain Struct Funct \\ DOI 10.1007/s00429-016-1189-x}

Unfortunately, in the original publication of the article, the table values of Tables 3 and 4 were published incorrectly. The corrected tables are given below and the original article has been updated to reflect this change.

The online version of the original article can be found under doi:10.1007/s00429-016-1189-x.

Sonja C. Huntgeburth

sonja.huntgeburth@mail.mcgill.ca

1 Cognitive Neuroscience Unit, Montreal Neurological, Institute and Hospital, McGill University, 3801 University St., Montreal, QC H3A 2B4, Canada

2 Department of Psychology, McGill University, 1205 Dr Penfield Avenue, Montreal, QC H3A 1B1, Canada 


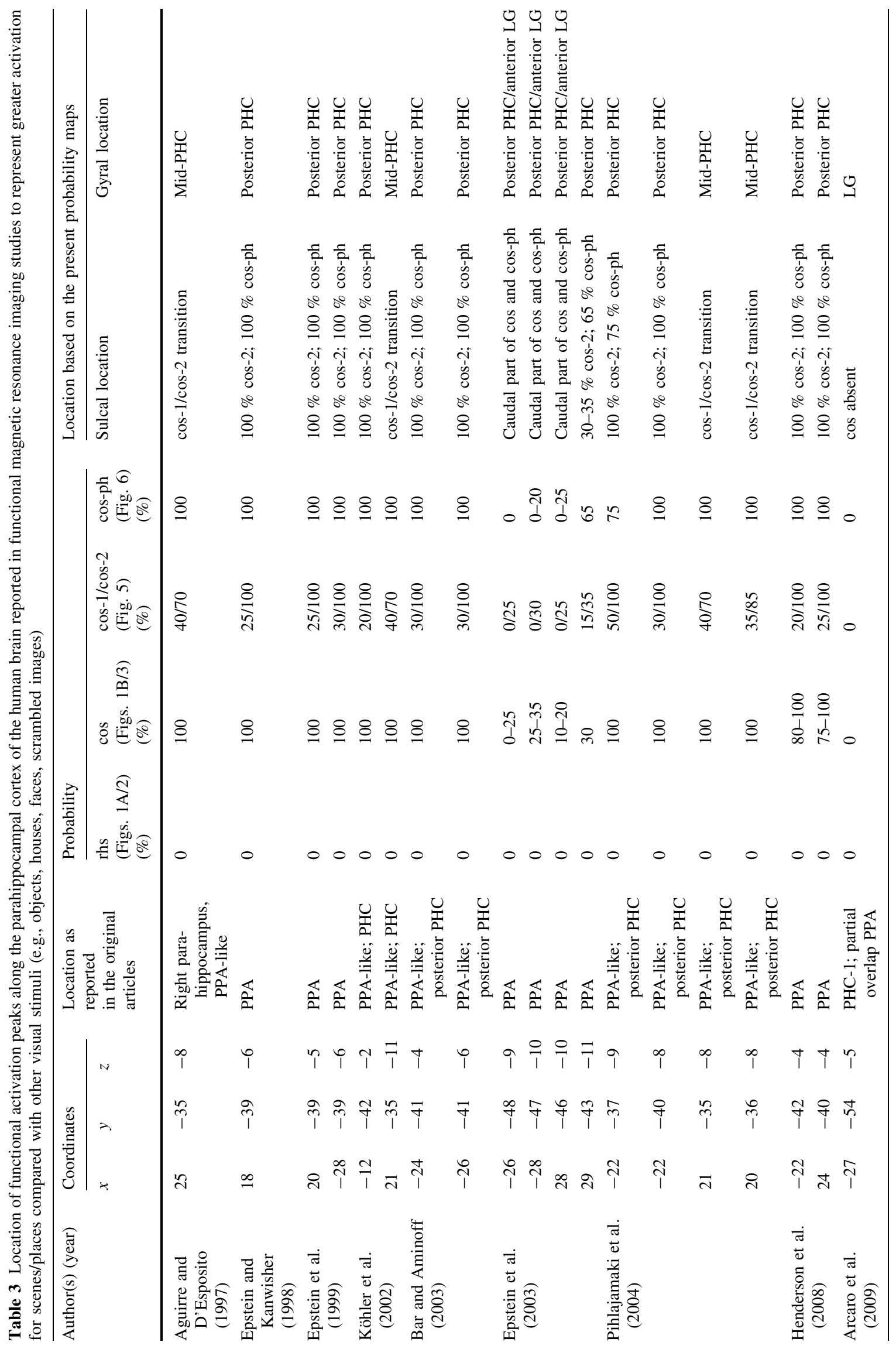




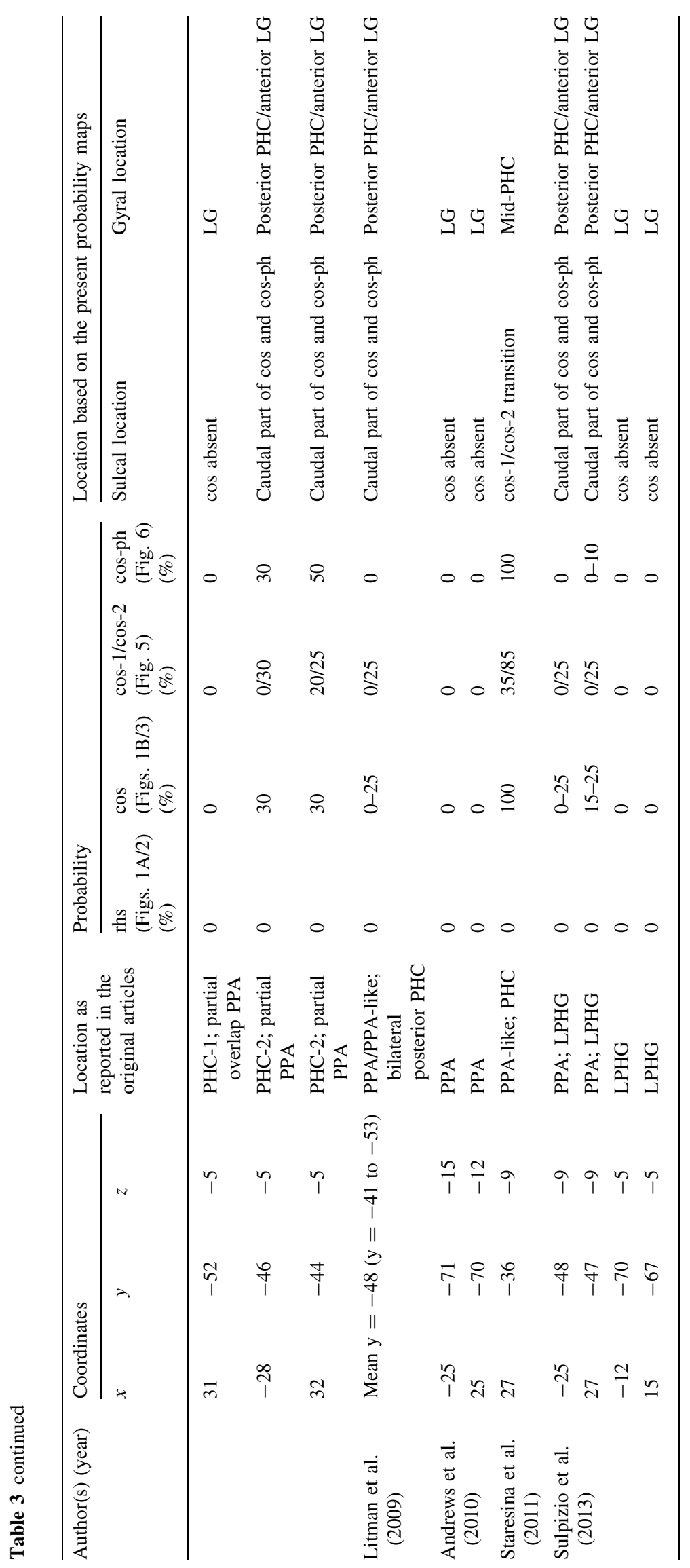




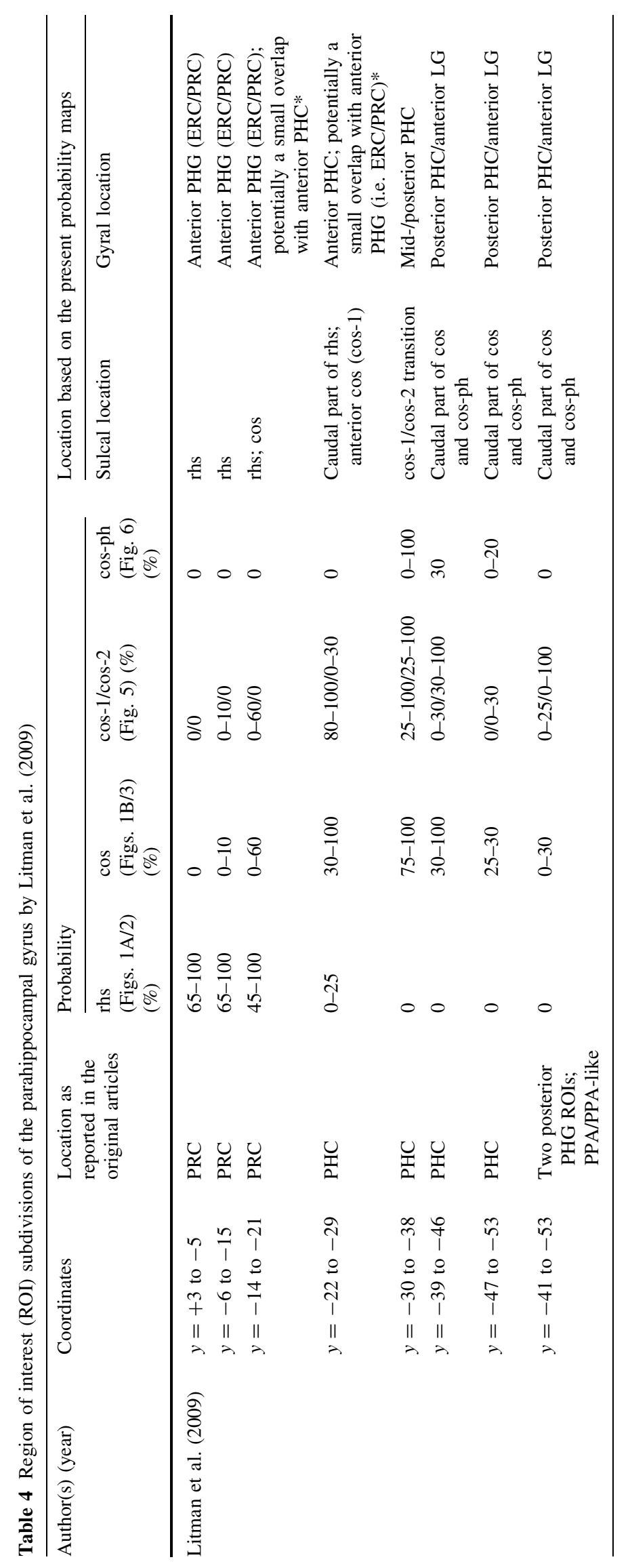

